\title{
OS CICLOS SEDIMENTARES E SEUS SIGNIFICADOS NA FORMAÇÃO DAS SEQÜÊNCIAS DEPOSICIONAIS CARBONÁTICAS ALBIANAS DA BACIA DE CAMPOS
}

\author{
RICARDO LATGÉ MILWARD DE AZEVEDO
}

\begin{abstract}
THE SEDIMENTARY CYCLES AND THEIR MEANING IN THE DEVELOPMENT OF THE ALBIAN - Different sedimentary cycle's scales detected in geophysical profiles helped to detail the stratigraphic and the genetic interpretation of Albian carbonates of the Campos Basin, offshore of Brazil. The study has defined ten Large Composed Sequence Scale (SCGE's), involving 1.4 to $0.3 \mathrm{My}$ periods, and more than seventy Small Composed Sequence Scale (SCPE's) of shorter periods. The halocinetic control is shown as most effective factor in the creation of space for the third order cyclotems. On the order hand, orbital parameters constrain the modulation of the faciologic succession of the allostratigraphic units of higher frequencies, being short eccentricity orbital cycles (100ka of duration) the best developed.

Based on wire-line log patterns of the SCGE's, it was possible to distinguish variations in the cyclothems formed in flat carbonate platform environments from those of deeper waters. It was recognized a difference in one order of magnitude in the accumulation rates between these two depositional environments. As consequence of the high resolution stratigraphy obtained, the detection of hiatus in the succession became more obvious, this will help in improove the precision of the geologic record.
\end{abstract}

\begin{abstract}
*ka-1000 years
Resumo A análise de ciclos de diferentes escalas, marcados nos perfis geofísicos, pode auxiliar no detalhamento estratigráfico e na interpretação genética do padrão estratal. Apreciação desta natureza, realizada nos carbonatos albianos da Bacia de Campos, possibilitou a identificação de dez seqüências compostas de grande-escala (SCGE's), envolvendo períodos de 1,4 a 0,3 Ma., e mais de sete dezenas de seqüências compostas de pequena-escala (SCPE's). O controle halocinético, superimposto à subsidência térmica, apresenta-se como o fator mais relevante na criação de espaço para a sedimentação dos ciclotemas de terceira ordem. Os fenômenos orbitais cumpriram um papel significativo na modulação da sucessão faciológica das unidades aloestratigráficas de mais alta freqüência, destacando-se aqueles associados à excentricidade curta (100ka* de duração).

O comportamento das curvas geofísicas nas SCGE's permitiu distinguir variações entre os ciclotemas formados em ambientes de plataforma carbonática rasa e aqueles acumulados em locais mais profundos. Reconheceu-se a diferença de aproximadamente uma ordem de grandeza nas taxas de acumulações entre os dois ambientes deposicionais. Com o detalhamento estratigráfico, os hiatos tornaram-se mais evidentes, contribuindo para ampliar a precisão da correlação geológica.
\end{abstract}

*ka-1000 anos

INTRODUÇÃO Seqüências estratigráficas podem apresentar padrões repetitivos, resultantes de processos sedimentares locais, designados de autociclos, ou refletirem mudanças climáticas ou hidrográficas regionais, caracterizando os alociclos (Fischer, 1986). Desde o final do século XIX, Gilbert (apud Fischer, op. cit.) percebeu que unidades litológicas, compostas por alociclos regulares preservavam os sinais precessionais $\mathrm{e}$ podiam ser usados como geocronômetros. Atualmente, a idéia de que variáveis astronômicas deixam traços no registro sedimentar tornou-se amplamente aceita, passando a ser referida como teoria de Milankovitch.

A teoria de Milankovitch ou de indução orbital parte do pressuposto que o sistema climático terrestre é fortemente afetado por oscilações periódicas nos valores de insolação, geradas pela variação cíclica dos parâmetros orbitais. Se preservadas adequadamente nos sedimentos, tais modificações ambientais astronomicamente induzidas definirão unidades litológicas rítmicas, cujas variações de espessura poderão expressar relações similares àquelas existentes entre os períodos conhecidos das variáveis orbitais da Terra (400 e 100 ka para a excentricidade, 41 ka para a obliqüidade e 2le 19 ka para a precessão).

Procurando investigar a potencialidade da ciclicidade sedimentar no refinamento estratigráfico, testou-se a técnica da análise espectral na subdivisão dos carbonatos albianos da Formação Macaé, Bacia de Campos. A integração dos novos dados com informações sedimentológicas, bioestratigráficas, sísmicas e marcos grafoelétricos permitiu alcançar resoluções geocronológicas superiores às até então inferidas para essa unidade litoestratigráfica.

PADRÕES E MÉTODO ANALÍTICOS PARA CICLOS CARBONÁtiCOS Num sistema carbonático, as seqüências se apresentam sob a forma de numerosos ciclos sedimentares empilhados em diferentes ordens. Geralmente, a unidade básica é formada por uma sucessão de fácies sedimentares indicava de ambiente deposicionais progressivamente mais rasos, definindo um padrão shallowing-upward (arrasamento para o topo). Para justificar esta corriqueira resposta sedimentar, Kendall e Schlager (1981) apresentaram um modelo evolutivo que contempla três estágios, partindo do afogamento de plataformas expostas ou rasas. Segundo eles, o padrão estratal reflete o crescimento vertical não-linear da fábrica carbonática em resposta à criação de espaço deposicional. A evolução do processo pode ser acompanhada num gráfico tempo versus crescimento da produção carbonática, tendo como elemento de referência o espaço disponível (Fig. 1). Normalmente, a taxa de produção tende a apresentar um contorno sigmoidal estando defasada daquela que registra a criação de espaço.

A primeira das fases, designada de start-up, representa a inundação da plataforma, que se faz numa taxa superior ao 
potencial de crescimento do ecosistema carbonático, estabelecendo condições batimétricas desfavoráveis à produção carbonática, que acaba concentrando-se em paleoaltos. Resta a maior parte da área inundada o suprimento de carbonatos finos, com forte contribuição pelágica, justificando as eletrofácies mais radioativas e fechadas (é mais facilmente compactada) nos perfis de poços. Um desenho com a forma de sino, ou do tipo give-up, segundo o modelo de Soreghan e Dickson (1994), é a representação esperada para os perfis de RG para uma evolução faciológica dessa natureza (Fig. 2).

A retomada com maior pujança do processo de sedimentação se efetiva com a redução progressiva da taxa de subida relativa do nível do mar. Logo, as condições tornar-se-ão ótimas, reinstituindo a capacic ade produtiva plena da plataforma carbonática. $\mathrm{O}$ espaço di ponível passa então a ser preenchido por sucessivas fácies que caracterizam o processo de arrasamento e de aumento da energia das condições deposicionais, o típico padrão shoaling-up. Esta etapa de restauração do sistema carbonático foi designado de catch-up, em referência ao padrão de perfil formado (Kendall e Schlager, 1981)

A fase final de evolução, chamada de keep-up, é aquela onde o crescimento carbonático atinge sua pujança máxima e acompanha pari passu a taxa de variação relativa do nível do mar. Estabelece-se um regime de progradação sedimentar, cuja conseqüência é a expansão das áreas de plataformas carbonáticas rasas. Com o desenrolar do processo, reduz-se progressivamente o espaço disponível para atuação da "fábrica de carbonato" e o sistema tende a se estabilizar num regime deposicional de in-

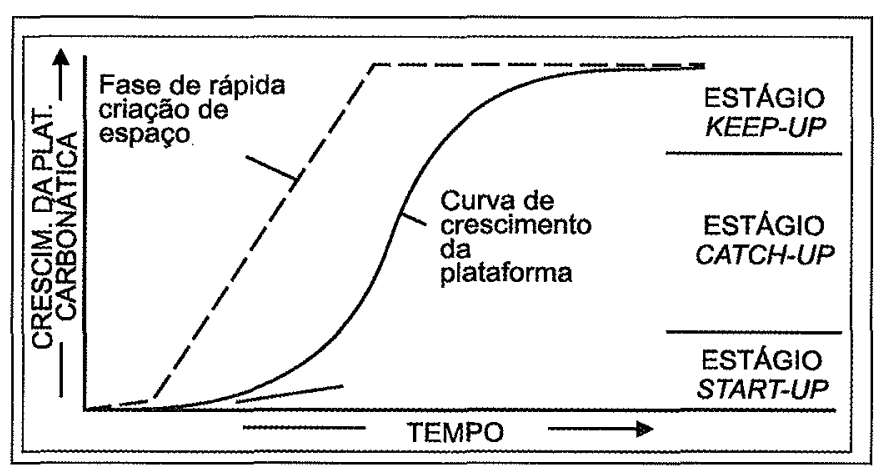

Figura 1-Curvadecrescimento do sistema carbonático, considerando a forte influência orgânica na acumulação destes sedimentos. Na primeira fase, há um retardo na ocupação do novo espaço criado (Start-up). No estágio Catch-up, a produção carbonática supera a taxa de criação de espaço, enquanto na fase final (Keep-up) a produção sedimentar passa a acompanhar, pari passu, a reduzida taxa de acomodação (modificado de Schlager, 1992) termaré a supramaré, até eventualmente ser interrompido, por exposição, quando de uma queda relativa do nível do mar. Nesse processo são formados ciclos com padrão assimétrico, do tipo funil, que evoluem para os simétricos serrilhados até aqueles do pico simples, representando a evolução dos ciclos de catch-up para os de keep-up, segundo o modelo genérico proposto por Soreghan e Dickson (1994), como mostrado na figura 2.

No método de detalhamento estratigráfico de sistema carbonático, adotado por Wrigth e Bruchette (1996), oferece modelos esquemáticos representando diferentes geometrias estratais observáveis em plataformas carbonáticas, a depender da variação da acomodação (ou variação relativa do nível do mar) no tempo (Fig. 3). A evolução faciológica e de espessuras das camadas definem configurações retrogradacionais, agradacionais e progradacionais que servem de critério para a identificação de seqüências deposicionais e seus tratos de sistemas. As camadas, ou conjuntos de camadas, com menos de $10 \mathrm{~m}$, com padrão shallowing-upward, características de ambiente de plataforma, representam individualmente seqüências elementares (ou seqüências simples, de Vail et al., 1991). Nos depósitos associados a ambientes carbonáticos marinhos mais profundos, onde o processo de rebaixamento relativo do nível do mar não é suficiente para alterar substancialmente a oferta de sedimentos carbonática, a unidade deposicional básica está representada, comumente, pelo par calcário/marga.

$\mathrm{O}$ arranjo cíclico observado na combinação de unidades elementares define as seqüências compostas de pequena-escala (small-scale depositional sequence), que podem chegar a dezenas de metros de espessura. O agrupamento destas unidades compõe a seqüência de grande-escala (large-scale depositional sequence), que alcançam a ordem de centenas de metros. Normalmente, na plataforma, apresentam evolução de fácies com tendência transgressiva-regressiva. $O$ enquadramento terminológico adotado para as seqüências nessa fase descritiva evitou uma vinculação explicita a períodos temporais. Os conceitos Vail et al. (1991) são seguidos no que se refere ao reconhecimento das superfícies-chaves, ou seja os limites de seqüências, superfícies transgressivas e superfícies de inundação máxima para as diferentes unidades aloestratigráficas.

A determinação da ciclicidade sedimentar e sua periodicidade pode ser obtida procedendo num estudo espectral de uma série de medidas do objeto estudado feitas seqüencialmente no tempo e registradas num periodograma. Esse gráfico registra, na ordenada, a densidade do espectro de potência e, na abscissa, a frequiência de oscilações dos harmônicos, representada pela razão ciclo/intervalo de amostragem. O comprimento de onda ou o período de cada freqüência significativa é obtido dividindo o intervalo de amostragem pelo número de ciclos, que é listado pelo programa. Através da comparação de razões dos valores destacados no periodograma com razões entre períodos orbitais de Milankovitch, identifica-se se houve a indução orbital no re-

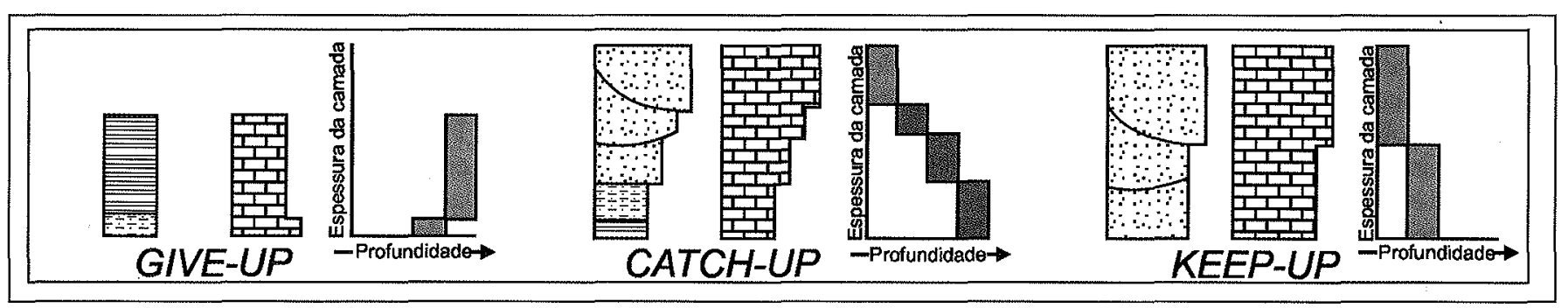

Figura 02- Comparação entre os principais padrões de empilhamento de sistemas siliciclásticos e plataformas carbonáticas. A direita de cada conjunto de par há a indicação da evolução batimétrica do ambiente deposicional (modificado de Soreghan e Dickinson, 1994). 


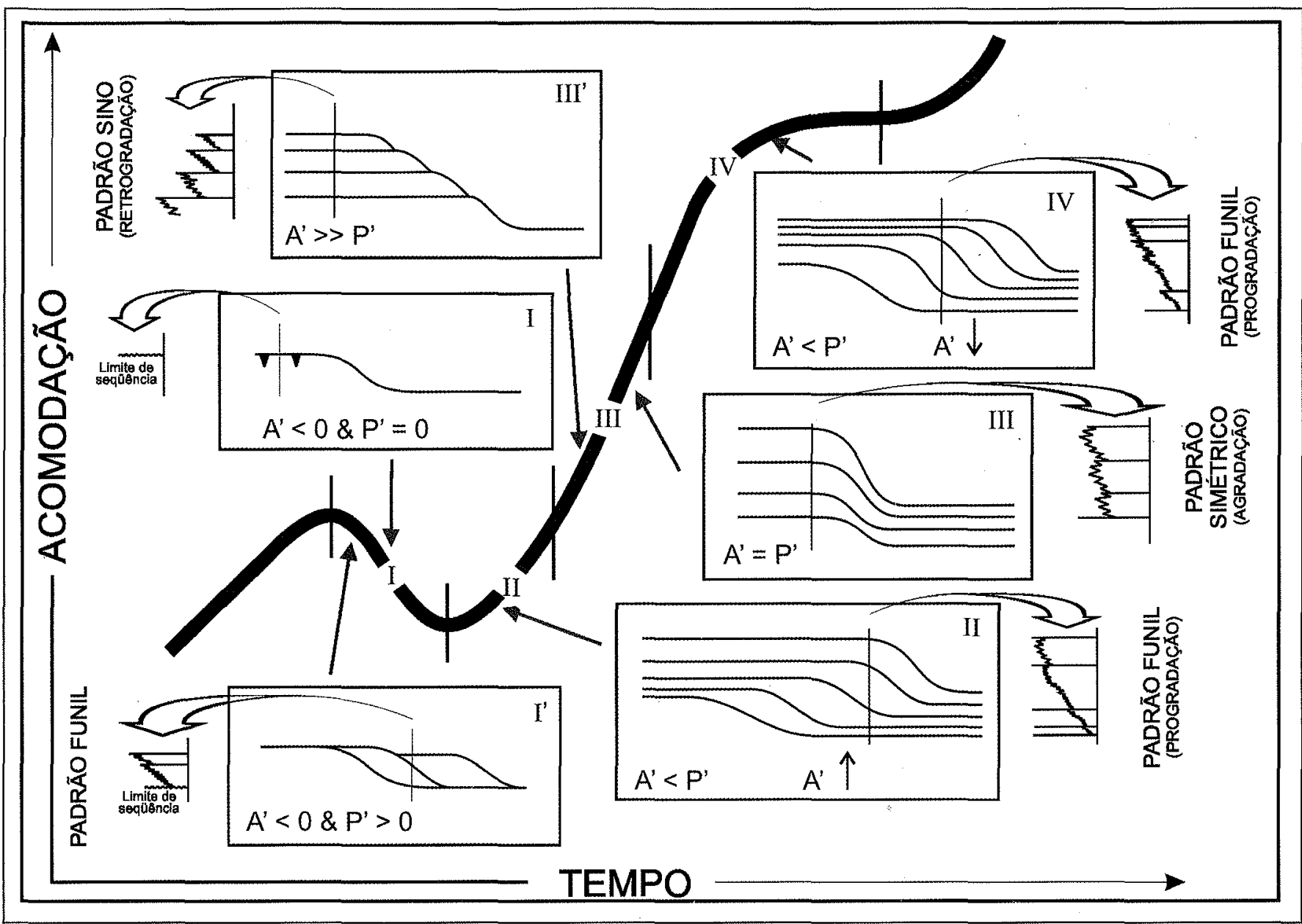

Modelos esquemáticos representando diferentes geometrias estratais observáveis em plataformas carbonáticas com a variação da acomodação (ou variação relativa do nivel do mar) no tempo. A magnitude dos parâmetros acomodação (A) e produção de sedimentos $(P)$ é mostrada no canto inferior esquerdo de cada diagrama. Os perfis registram o comportamento da variável Raios-Gama, com o aumento da argilosidade para a direita (modificado de Wrigth e Burchette, 1996)

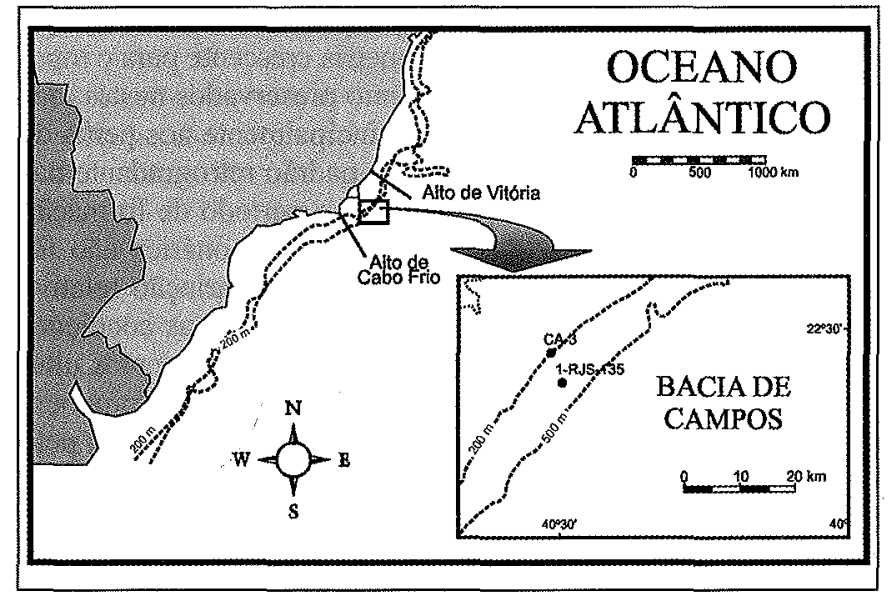

Mapa de localização da Bacia de Campos na margem continental brasileira e as posições dos poços estudados.

gistro sedimentar (Azambuja, 1990).

É bom lembrar que, no caso do registro sedimentar, a adoção dessa técnica pressupõe considerar constante a taxa de acumulação para o intervalo analisado, assumindo uma relação direta e linear entre profundidade e tempo. Se a seção apresenta variações no aporte sedimentar, é conveniente optar por processamento analítico seguindo etapas diferentes, tratando isoladamente os segmentos de seção que exibam regularidades na sedimentação.

ANÁLISE DO PADRÃo ESTRATAL DA SEÇÃo dO 1-

RJS-135 O detalhamento estratigráfico da Formação Macaé limitou-se aos poços 1-RJS-135 e CA-3 (Fig. 4). Ambas as seções exibem padrões rítmicos nos perfis geofĩsicos, lembrando que o 1-RJS-135 é a seção de referência da Formação Macaé e dos membros Quissamã e Outeiro (Rangel et al. 1994). Os resultados da análise de ciclicidade de intervalos específicos destas unidades litoestratigráficas serviram de base para as deduções apresentadas neste artigo. A inclusão do CA-3 foi determinada para testar a consistência lateral dos ciclos.

As figuras 5 e 6 registram, na escala de profundidade, os perfis geofísicos de Raios-Gama (RG), Resistividade (ILD) e Sônico (DT), e as unidades bio-, para- e cronoestratigráfico reconhecidas por Azevedo (2001) para cada os poços 1-RJS-135 e CA-3.

A figura 7 exibe a compartimentação em seqüências de várias ordens obtida para o poço 1-RJS-135. Os diferentes padrões e sua sucessão vertical, incluindo a tendência de espessamento ou adelgaçamento das camadas, contribuíram para a delimitação de sequiências e seus tratos de sistema. Sobre a camada de dolomito, que marca a base da Formação Macaé, sucedem-se mais 


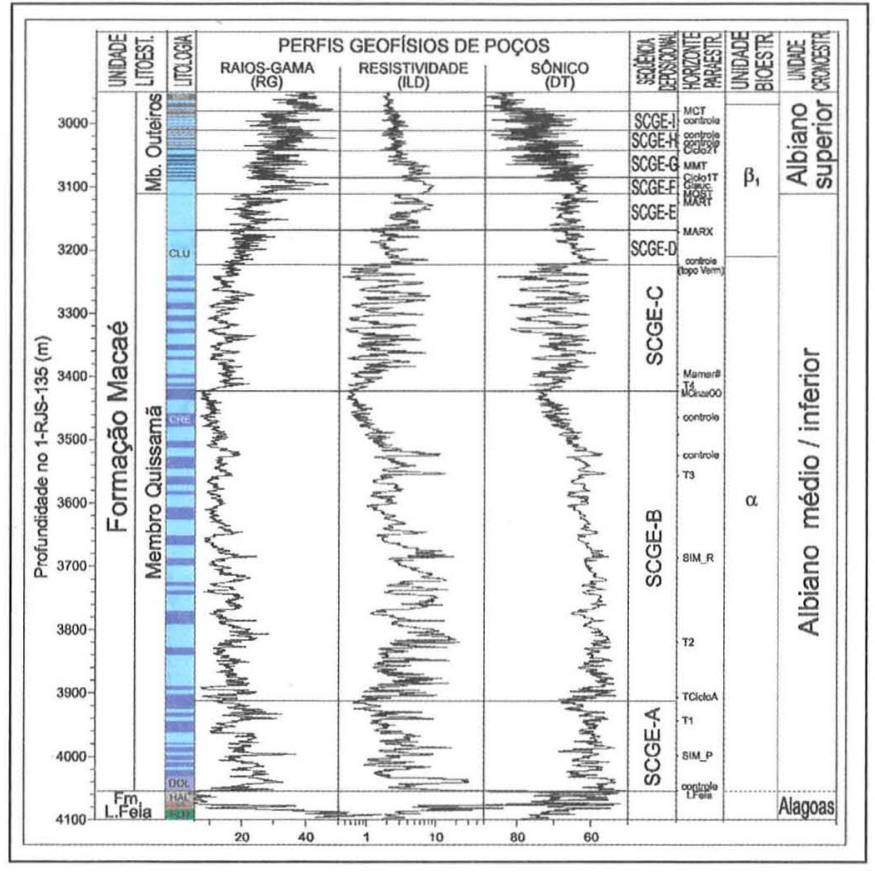

Figura 5 - Variações dos parâmetros geofisicos e os limites das unidades bio- e paraestratigráficas ao longo do poço 1-RJS135. A indicação cronoestratigráfica apoia-se exclusivamente em indicações bioestratigráficas.

de $1 \mathrm{~km}$ de carbonatos, sendo cerca de nove décimos desse total representado pelo Membro Quissamã. Os estratos mais superiores correspondem ao Membro Outeiro.

Os carbonatos do Membro Quissamã são formados dominantemente pelo empilhamento de ciclos com textura com granulocrescência ascendente, cada um correspondendo a uma seqüência elementar. Registram uma gama variada de fácies sedimentares, que caracteriza uma evolução ambiental do tipo shoaling-up, indicando um progressivo aumento da energia do sistema, pari passu à redução de batimetria. Os calcilutitos definem o início do ciclo, representando episódios de afogamento sobre fácies mais rasas da unidade subjacente.

As generalizações apresentadas por Spadini (1992) servem à interpretação da sucessão sedimentar observada no poço 1RJS-135, com relação aos carbonatos Quissamã. Nos perfis geofísicos, se destacam os ciclos com espessuras que variam de 10 a 50m (Fig. 7). Essas unidades modulam oscilações de mais altas freqüências, com espessuras de poucos metros, que não têm a mesma regularidade. Também são moduladas por ciclos de período bem mais longo, representados por centenas de metros de sedimentos, que comprovam o caráter fractal do arranjo oscilatório. Ajustando essas unidades de diferentes ordens de espessura à classificação de Pasquier e Stasser (1997), os ciclos mais delgados foram entendidos como representantes das seqüências elementares (SE). Os intermediários, que são os mais evidentes nos perfis geofísicos, estabelecem às seqüências compostas de pequena-escala, também designada pelo mnemônico SCPE. As oscilações com centenas de metros correspondem às seqüências compostas de grande-escala (SCGE).

A unidade de ordem intermediária, a SCPE, foi escolhida para descrição e detalhamento estratigráfico do conjunto de seções trabalhadas. No poço 1-RJS-135, nos carbonatos Quissamã, foram contados 41 dessas unidades, que delineiam, nos perfis geofísicos, formas simétricas, serrilhadas ou lisas, e assimétricas como sino ou funil (Fig. 7). Os diferentes padrões estão distribuídos de modo relativamente organizado na seção,

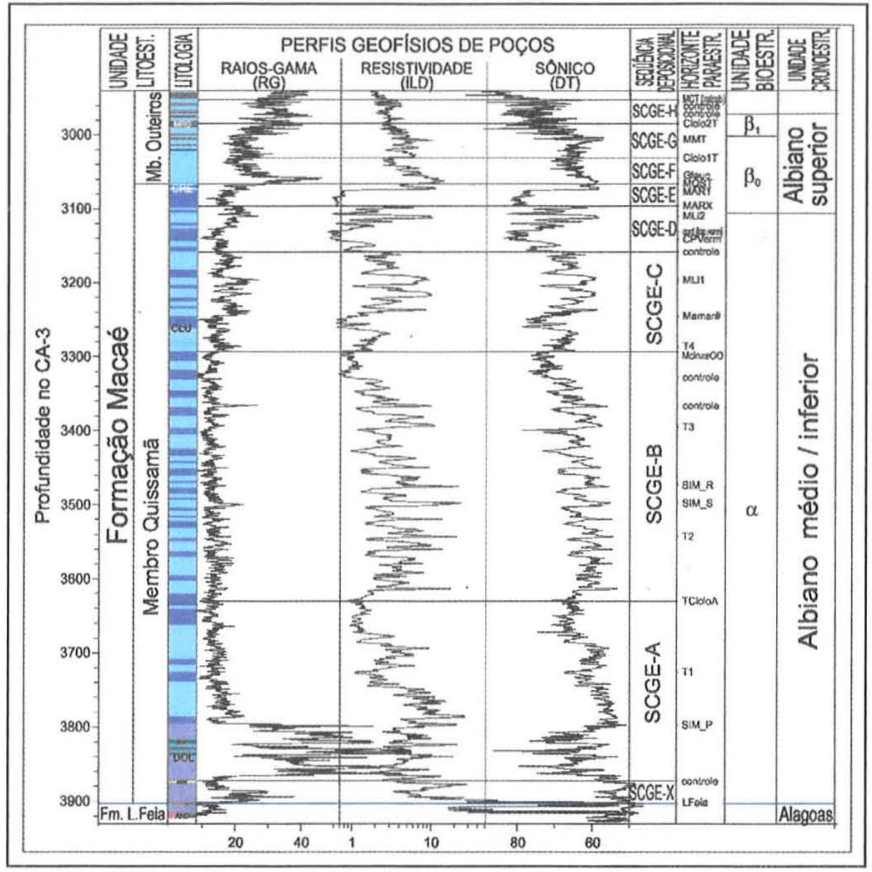

Figura 6 - Variações dos parâmetros geofísicos e os limites das unidades bio-, paraestratigráficas ao longo do poço $C A-3$. A indicação cronoestratigráfica apoia-se exclusivamente em indicações bioestratigráficas.

permitindo a caracterização de cinco seqüências compostas de grande-escala. O intervalo 3423 a $3222 \mathrm{~m}$ registra a SCGE-C, que agrupa 11 seqüências compostas de pequena-escala. Da base para o topo se sucedem duas SCPE's com padrão assimétrico do tipo sino, duas simétricas serrilhada, duas assimétricas do tipo funil e as seis mais superiores evoluindo das simétricas serrilhadas aos picos simples, com as espessuras que tendem a diminuir em direção ao topo.

As duas seqüências compostas de pequena-escala, com padrão assimétrico do tipo sino (SCPE-Ca e SCPE-Cb), têm cerca de $25 \mathrm{~m}$ de espessura e congregam, cada uma, entre 4 e 5 seqüências elementares, com granulometria crescente para o topo. São os sucessivos picos de afogamento preservados nestas unidades fundamentais, evidenciados principalmente nos perfis de resistividade e sônico, que definem o padrão retrogradante nas duas SCPE's. Interpreta-se que durante o período de formação dessas seqüências compostas, a produção carbonática não foi suficiente para acompanhar o incremento da variação relativa do nível do mar, ou seja, da acomodação. Assim, as condições batimétricas tornaram-se mais profunda nos afogamentos ulteriores à acumulação de cada seqüência elementar. Compõem portanto um arranjo similar ao III', registrado na figura 3 , pelo qual as unidades SCPE-Ca e SCPE-Cb representariam o trato de sistema transgressivo da SCGE-C.

Por sua vez, as SCPE's Cc e Cd, exibem forma simétrica, serrilhada. Neste caso, as unidades elementares moduladas não se apresentam com nitidez, embora se conte nove ciclos de mais alta freqüência nos $47 \mathrm{~m}$ compreendidos pelas duas seqüências. A forma simétrica é sugestiva de um certo equilíbrio na taxa de acomodação acompanhada pelo aumento na produção carbonática. A conseqüência de um processo dessa natureza está na substituição do padrão retrogradacional pelo agradacional, o que, no âmbito de uma seqüência deposicional, aponta para a passagem do trato de sistema transgressivo para o de nível de mar alto. Essa conclusão pressupõe a presença de uma superfície de inundação máxima (SIM), que foi marcada na profundidade 


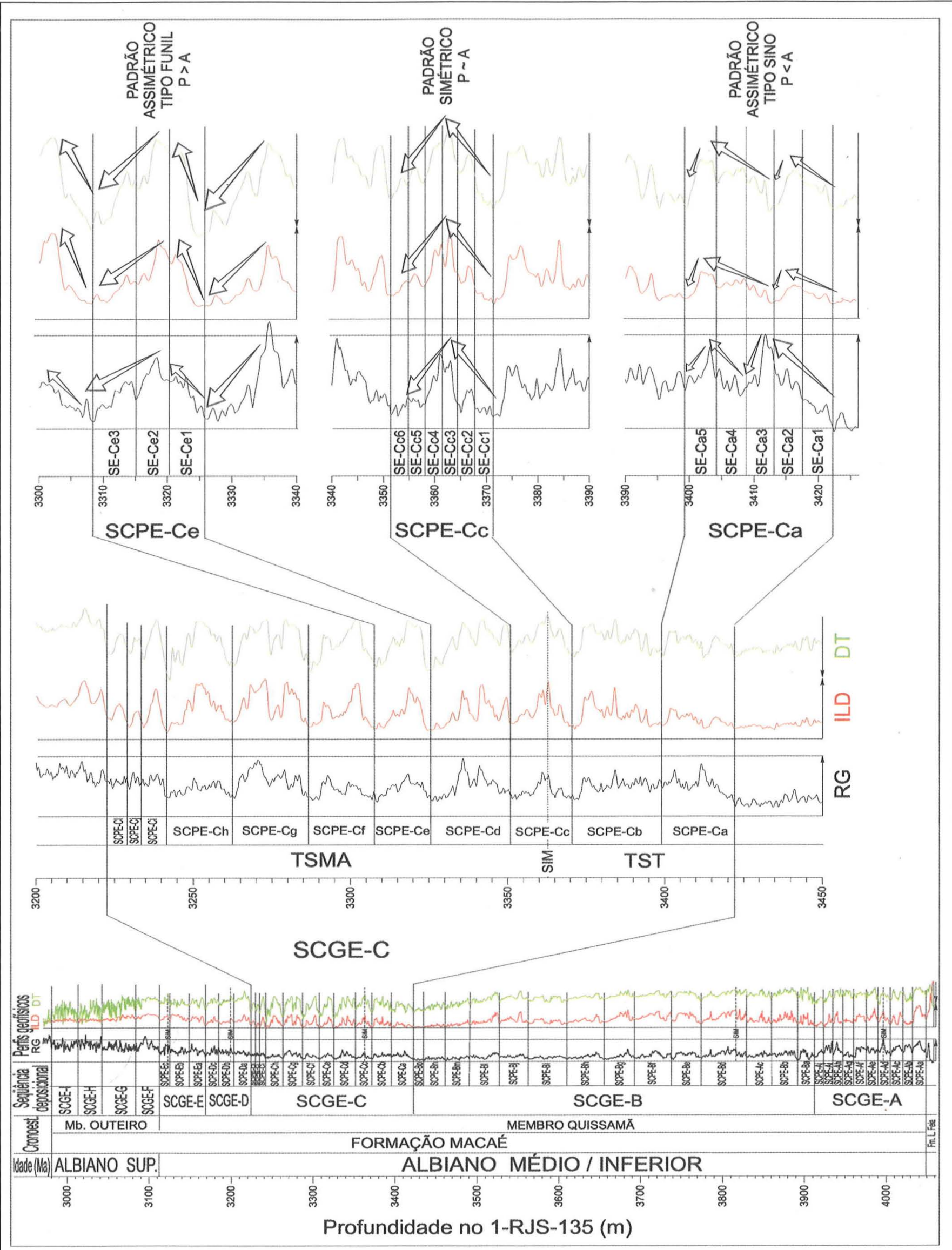

Figura 7 - Os carbonatos Macaé no poço 1-RJS-135 e sua compartimentação em seqüencias de diferentes ordens. A sigla SCGE é utilizada para indicar as seqüencias compostas de grande-escala. As SCPE's são aquelas compostas de pequena-escala, que congregam as seqüências elementares (SE'S). O TSMA e TST representam, respectivamente, os tratos de sistemas de nível de mar alto e o transgressivo. O mnemônico SIM significa superfície de inundação máxima. 
de 3364m, onde há um máximo de RG e ILD (Fig. 7)

As duas seqüências compostas de pequena-escala seguintes, SCPE-Cd e SCPE-Ce, mostram um padrão assimétrico com forma de funil e espessuras inferiores às das subjacentes, não ultrapassando de $20 \mathrm{~m}$. Estes empilhamentos de rocha reproduzem, numa escala maior, o ciclo básico de shallowing-upward das seqüências elementares, com calcilutitos concentrados na base de cada unidade. $O$ padrão serrilhado bem desenvolvido no perfil de ILD comprova a existência de ciclos sedimentares de espessuras menores. As inflexões positivas observadas no limbo de descida da curva de resistividade da seqüência SCPE-Ce evidenciam os recorrentes afogamentos vinculados a oscilações de freqüências mais altas, as seqüências elementares.

As limitações de resolução estratigráfica na detecção das seqüências elementares se tornam mais crítica nas seis seqüências compostas de pequena-escala que compõem a porção superior da SCGE-C. O padrão apresentado por estes ciclos é o simétrico, evoluindo de serrilhado para liso, em consonância com a redução na espessura das unidades que cai aproximadamente de 15 para $5 \mathrm{~m}$. O arranjo exibido pela a sucessão de seqüencias compostas de pequena-escala indica uma mudança da geometria deposicional de agradacional para progradacional, no decorrer do trato de sistema de mar alto da SCGE-C. O processo de criação de espaço deposicional tornou-se insuficiente para acomodar o volume de carbonatos produzidos $(\mathrm{A}<\mathrm{P})$, justificando o contorno simétrico liso observado principalmente na curva de ILD, próprio da fase de keep-up.

Nesse conjunto de seqüência de pequena-escala destoa apenas a SCPE-Ch, que apresenta um padrão caracteristicamente simétrico serrilhado e espessura maior do que as demais unidades. A resposta diferenciada, aparentemente aperiódica, é entendida como produto de um incremento momentâneo da acomodação. Admitindo como premissas o comportamento cíclico da eustasia e uma taxa constante da subsidência termal para a Bacia Campos durante o Albiano (Chang et al., 1991), a espessura anômala da SCPE-Ch pode ser imputada à criação de espaço adicional por halocinese.

Um outro aspecto que merece ser discutido, refere-se à opção de associar as três últimas seqüências de pequena-escala (SCPE-Ci, SCPE-Cj e SCPE-Cl) ao final do trato de nível de mar alto. Observando o modelo apresentado na figura 3, constata-se que o empilhamento de seqüências elementares num trato de sistema de nível de mar baixo se confunde com àquele do final do trato de mar alto. A escolha por este último está atrelada ao modelo rampa carbonática indicado para o Macaé (Esteves et al., 1987). Outro argumento que suporta esta interpretação está na ausência de ingresso expressivo de siliciclásticos. A esta constatação se soma o fato de que, de uma forma geral, as demais seqüiências de grande-escala do poço 1-RJS-135, não mostram evidência de terem preservado tratos de nível de mar baixo.

Tendo como referência a metodologia acima descrita, Azevedo (2001) reconheceu, no Membro Quissamã, no poço 1-RJS135 , outras quatro seqüências de grande escala, designadas de SCGE's A, B, D e E. A mais antiga delas, a SCGE-A, destaca-se pela presença de camada de dolomita na base, assentada sobre os evaporitos da Formação Lagoa Feia, sobre o qual se sucedem ciclos de shallowing-upward. Por sua vez, os sedimentos mais jovens do Membro Quissamã, pertencentes a SCGE-E, diferenciam-se de forma abrupta do pacote de calcilutitos que marca a base do Membro Outeiro.

O Membro Outeiro, da Formação Macaé, também conhecido como Macaé Superior (Falkenhein, 1981), tem como perfil de referência o intervalo entre 3111 e $2860 \mathrm{~m}$ do poço 1-RJS-135 (Rangel et al., 1994). A seção neo-albiana está limitada às profundidades de 3111 a $2980 \mathrm{~m}$ (Fig. 5) e é produto de deposição em ambientes marinhos bem mais profundos do que o Mem- bro Quissamã (Azevedo, Gomide, Viviers, 1987), conseqüentes ao afogamento da plataforma carbonática ocorrida no início do neo-albiano (Spadini, 1982).

Em termos composicionais, o Membro Outeiro é constituído por calcilutitos, sobrepostos por margas e folhelhos. A sucessão de fácies delineiam contornos diferenciados nos perfis geofísicos de poços, que levaram Spadini (1982) a subdividir a unidade, de modo informal, da base para o topo, nos intervalos Maciço, Chalk e Argiloso, com os dois primeiros acumulados no neo-albiano e Intervalo Argiloso associado ao neocenomaniano/eoturoniano (Azevedo, Gomide, Viviers e Hashimoto, 1987). O "Intervalo Maciço" recebeu essa designação devido à feição da curva do sônico. É constituído por calcilutitos bastante cimentado, com pitonelidos e cocolitos. Por sua vez, o pacote intermediário mostra no perfil sônico um padrão serrilhado, representando a alternância de camadas de calcilutitos e margas. A designação de "Intervalo Chalk" foi determinada pela abundância de pitonelas e cocolitos na matriz. O pacote mais superior, o "Intervalo Argiloso", é formado por margas e folhelhos, com ocorrência subordinada de calcilutito argiloso.

O método ora adotado de delimitação de seqüências e seus tratos sistema, com base em padrões de perfis geofísicos de poços, permite oferecer uma compartimentação estratigráfica diferente para o Membro Outeiro. O significado do regime cíclico, manifesto no par calcilutito/ marga, que ocorre de forma generalizada no Albiano superior da Bacia de Campos, foi objeto de várias pesquisas consolidadas em Azevedo (2001).

A premissa de uma origem alocíclica para os ritmitos calcilutito/marga leva a admitir a presença de uma seqüência deposicional elementar em cada um desses pares litológicos. A dúvida está em saber a que trato cada fácies pertence, se é que há uma resposta única para questão. No intervalo do Membro Outeiro do poço 1-RJS-135, correspondente ao Albiano, é possível observar quatro ciclos sedimentares distribuídos entre as profundidades 3115 a 3084, 3084 a 3042, 3042 a 3012, e 3012 a $2980 \mathrm{~m}$ (Fig. 8). Como acumularam em ambiente nerítico externo a batial superior (Azevedo, Gomide e Viviers, 1987), sob taxa de acumulação bastante reduzida (o neo-albiano durou cerca $6,1 \mathrm{Ma}$ ), optou-se por interpretá-los como resultante de processos de oscilação relativa do nível do mar de magnitude similar ao das seqüêencias compostas de grande-escala. Essa unidade maior modula outras de menor escala, num previsível arranjo fractal, que tem como unidade básica o par calcilutito/marga.

Além das características litológicas, que determinam o aspecto singular nos perfis geofísicos do "Intervalo Maciço", a unidade representa um estágio de transição no comportamento da curva de Raios-Gama. Em todas as unidades de grande-escala anteriores (SCGE-A a SCGE-E), o perfil RG mostra um razoável grau correspondência direta com o de Resistividade e inversa com o Sônico. Nas unidades posicionadas em níveis estratigráficos mais altos (SCGE-G a SCGE-I), a correspondência entre essas variáveis se faz de modo oposto. As respostas obtidas para o "Intervalo Maciço" mostram a independência entre os valores de $\mathrm{RG}$ e as variáveis ILD e DT (Fig. 8).

Nos carbonatos de água rasa do Membro Quissamã, as concentrações extremamente baixas de argila e a relativa estabilidade ambiental, definida por ciclos periódicos do tipo shallowing-upward, possibilitaram uma resposta comum nos perfis geofísicos de poços. Com as transformações ocorridas na bacia no final do meso-albiano/ início neo-albiano, houve o aprofundamento do ambiente deposicional e a ampliação do aporte de terrígenos, culminando com deposição rítmica de calcilutitos/margas. Nesses pares, parece mais razoável admitir que o calcilutito represente a fácies acumulada na fase de afogamento (o trato transgressivo). Por sua vez, a marga é entendida como produto do trato de mar alto, podendo também estar associada 


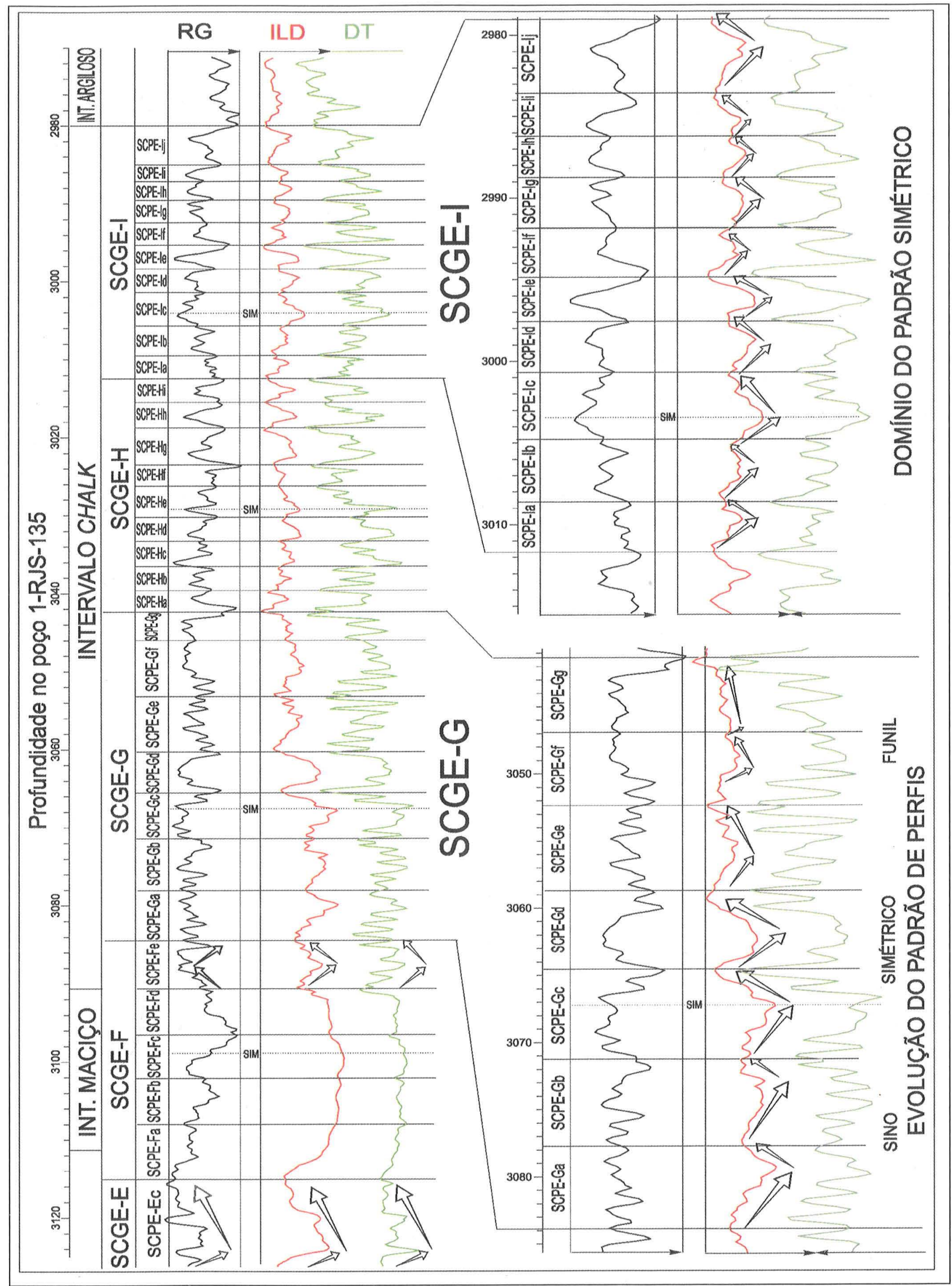

Figura 8 - Compartimentação do Mb. Outeiro em seqüências de diferentes ordens. Observar a variação no padrão do perfil ILD para a SCGE-G, com ciclos assimétricos e simétricos. Já na SCGE-I, os ciclos são dominantemente do tipo simétrico. 
ao trato de nível de mar baixo, acumulado em concordância com a seqüência subjacente. $O$ modelo se apóia no padrão observado em toda a seção Quissamã, onde os calcilutitos representam normalmente a fase de afogamento. Os primeiros sedimentos acumulados após brusca inundação neo-albiana também são calcilutitos e registram valores de RG, ILD e DT que não diferem substancialmente dos carbonatos finos presentes no Membro Quissamã.

Acima do "Intervalo Maciço" ocorre a primeira SCPE a registrar, de modo explícito, a inversão na correspondência entre os valores de $R G$ e aqueles referentes aos parâmetros ILD e DT. Utilizando-se de setas, procurou-se destacar na figura 8 as diferenças no comportamento a última seqüência composta de pequena-escala do Membro Quissamã (SCPE-Ec) e a mais superior da SCGE-F. De um modo geral, os valores de Radioatividade não se alteram nos calcilutitos de afogamentos anteriores e ulteriores ao "Intervalo Maciço". A maior disponibilidade de argila no sistema é que provoca a inversão na resposta do perfil $R G$ frente ao ILD e DT. O destaque dispensado aqui a este aparente detalhe tem o objetivo de justificar situações geológicas onde os valores máximos de argilosidade podem estar representando trato de sistema de mar alto ou de mar baixo. A solução destoa da interpretação corriqueira em seçôes silicicláticas marinhas, onde valores elevados de $\mathrm{RG}$, associados à presença de argila, são lembrados como produtos do trato transgressivo, cabendo aos valores máximos a primazia de representarem superfícies de inundação máximas.

O ponto de vista da análise de sequiências deposicionais, o "Intervalo Chalk" está representado pelas unidades de grandeescala $\mathrm{G}, \mathrm{H}$ e I, além da última SCPE da unidade SCGE-F. O ciclo sedimentar designado de SCGE-G se estende de 3084 a $3042 \mathrm{~m}$ e permite a subdivisão em sete seqüência de menor escala (SCPE-Ga a SCPE-Gg). De acordo com o modelo modificado de Wrigth e Bruchette (1996), registrado na figura 3, o padrão de empilhamento das unidades menores sugere um arranjo retrogradacional, seguido por agradação e progradação das litofácies (Fig. 8). A superfície de inundação máxima, marcada a $3067 \mathrm{~m}$, representa um calcilutito fechado, com características similares daqueles do "Intervalo Maciço". No trato de mar alto, aumenta proporcionalmente a parcela de margas, que confere um decréscimo no perfil de ILD e aumento no DT. No perfil de RaiosGama, a maior presença de argila impõe valores mais elevados frente aos calcilutitos.

Os ciclos de grande escala associados as unidades SCGEH e SCGE-I modulam oscilações de mais alta freqüência, pertencentes provavelmente as ordens de seqüências composta de pequena-escala e seqüências elementares. Foram diferenciados 9 e 10 SCPE's em cada unidade de grande-escala, que congregam conjuntos de pares calcilutito/marga. A solução encontrada indica ter ocorrido alterações significativas na taxa de acumulação para o período de deposição dos calcário Quissamã e Membro Outeiro, questão esta que será discutida adiante.

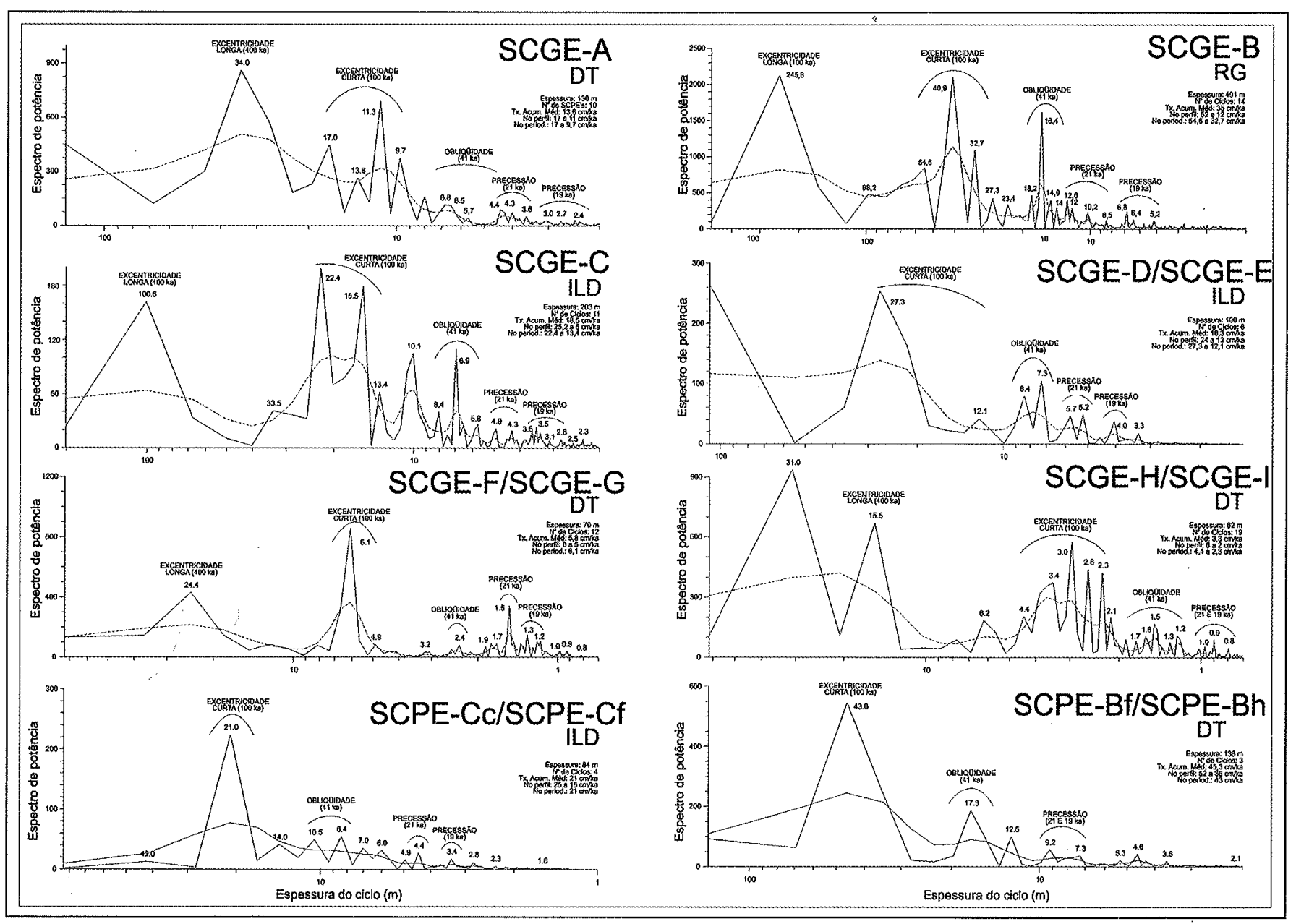

Figura 9 - Periodogramas referentes às séries de valores de $R G$, ILD e DT, representativos de seqüencias compostas reconhecidas no Albiano do poço 1-RJS-135. Os números sobre as curvas indicam as espessuras dos ciclos, em metros, que foram utilizados na comparação com a matriz dos periodos Milankovitch. As curvas suavizadas foram obtidas utilizando o algoritimo de Hamming, cotejando 7 medidas. 
ANÁLISE ESPECTRAL E O TEMPO ENVOLVIDO NOS CICLOS SEDIMENTARES O estudo referente à ciclicidade sedimentar da Formação Macaé compreendeu todo o intervalo Albiano, entre as profundidades de 4054 e $2890 \mathrm{~m}$. Para efeito da análise de séries temporais foram considerados 5371 valores de Raios-Gama (GR), Resistividade (RILD) e Sônico (DT), espaçados $20 \mathrm{~cm}$ entre si.

Antes de avançar na análise espectral das unidades que compõem o Macaé albiano, é interessante relembrar a ordem de grandeza do tempo envolvido no pacote sedimentar estudado. De acordo com a escala Bralower et al. (1997), o Albiano inferior congrega sedimentos acumulados entre 112,2 e $108,1 \mathrm{Ma}$, compreendendo, portanto um período de 4,1 Ma. O Albiano médio e Albiano superior formaram-se entre 108,1 e 105, e 105 e 98,9 Ma, correspondendo a períodos de 3,1 e 6,1 Ma, respectivamente.

As variações na taxa de acumulação admitidas para o carbonato Macaé estão suportadas em interpretações biocronoestratigráfica diversas, envolvendo surgimentos e extinções de organismos planctônicos, que têm amplitudes cronoestratigráficas bem definidas (Azevedo, 2001). A sucessão desses bioeventos indicam que o Membro Quissamã acumulou-se durante o eo/ meso-albiano, enquanto que a porção carbonática do Membro Outeiro, bem mais delgada, tem idade neo-albiana. A adoção dos critérios dos limites temporais, aceitos na Bacia de Campos, no intervalo examinado do poço 1-RJS135, implicaria em taxas de acumulação da ordem de $13,3 \mathrm{~cm} / 1000$ anos para a seção Quissamã, e 2,2 cm/1000 anos para os carbonatos albianos do Membro Outeiros.

Admitindo a origem alocíclica dos ciclotemas, há como especular preliminarmente sobre a natureza mais provável das SCPE's, que são as oscilações mais evidentes na seção. Dividindo o tempo envolvido na deposição dos membros Quissamã e Outeiro pela quantidade de ciclos que congregam, 41 e 31, chega-se a médias de duração dos ciclos de 173 e 197 ka. Valores dessa ordem de grandeza se inserem no espectro do fenômeno de excentricidade orbital, que tem períodos de 100 e $400 \mathrm{ka}$ (Berger, 1988). Como a preservação do registro sedimentar não se faz de forma integral, é razoável admitir que as SCPE's representem fundamentalmente os ciclos de excentricidade curta, correspondendo a intervalos de tempo com cerca de $100 \mathrm{ka}$.

Consideradas unidades de mesmo grau hierárquico, as nove SCGE's distribuídas pelos $1074 \mathrm{~m}$ de Albiano do poço 1-RJS135 têm espessuras diferentes, embora haja algumas que guardam grande similaridade entre si. Assim, optou-se por efetuar a análise espectral em etapas, apreciando, numa primeira fase, as ciclicidades de menor ordem. Exames foram realizados para todo o Albiano e para SCGE's em conjunto ou isoladas. Houve também situações que exigiram o processamento de intervalos menores, contemplando segmentos de seqüências que apresentam taxa de acumulação relativamente estabilizada. Este detalhamento visou obter uma melhor caracterização das oscilações de mais altas frequiências, eventualmente inseridas no espectro de Milankovitch.

A figura 9 apresenta os periodogramas com os melhores resultados para seqüências ou conjuntos de sequiências de grandeescala analisados. Ao lado de cada gráfico há o registro da espessura da SCGE, o número de sequiências de pequena-escala identificadas e as taxas de acumulação máximas e mínimas deduzidas das espessuras das SCPE e das soluções interpretadas a partir dos periodogramas. Na tabela 1, as soluções indicadas nos gráficos são confrontadas com as espessuras estimadas para os ciclotemas de diferentes ordem, obtidas das razões entre períodos de Milankovitch. Os valores foram calculados assumindo a correspondência dos SCPE's com o ciclo de excentricidade curta. Por exemplo, para os valores destacados no periodograma da SCGE-B (máximo de 54,6 e mínimo de $32,7 \mathrm{~m}$ ), estima-se que os eventuais ciclos de obliqüidade subordinados deveriam ter espessuras entre 22,5 e 13,4 m, admitindo uma razão de 100/41 entre os dois períodos orbitais comparados.

De um modo geral, os periodogramas apresentam soluções que demonstram o controle orbital sobre a sedimentação. $O$ fenômeno de excentricidade curta, com $100 \mathrm{ka}$ de duração, foi o que deixou os sinais mais marcantes. $O$ resultado confirma a conclusão de Sadler (1994) apontando esse parâmetro orbital como o de maior expressão entre carbonatos formados sob greenhouse, condição climática dominante no planeta durante o Albiano (Frakes et al., 1992).

Examinando em detalhe cada um dos gráficos registrados na figura 9, é possível discernir diferenças no grau de confiabilidade na análise espectral. No Membro Quissamã, onde as unidades foram construídas em ambiente exposto a taxas de acumulação maiores e mais variadas, o vínculo entre os ciclos sedimentares e os períodos de Milankovitch não se apresenta de forma tão explicita. O gráfico da SCGE-C é o que melhor exemplifica as distorções da solução matemática provocadas pela variação na taxa de acumulação. Nessa unidade de grande-escala, onze ciclotemas, com espessuras que variam de 27 a $5 \mathrm{~m}$, foram associados à excentricidade curta. No periodograma há sete picos contidos entre esses limites $(22,4 ; 15,5 ; 13,4 ; 10,1 ; 8,4 ; 6,9 ; \mathrm{e}$ $5,8)$, número que se reduz à três, utilizando-se da solução suavizada da função espectro de potência (linha interrompida). A

Tabela 01 - Correspondência entre os periodos de Milankovitch e os ciclos destacados nos periodogramas do 1-RJS-135. Os valores registram as espessuras indicadas nos picos do periodogramas. Quando dois são indicados, representam as soluções máxima e mínima possíveis. A coluna espessura indica os valores máximos e mínimos das SCPE's em cada SCGE's. As taxa de acumulação registram os máximos e mínimos indicados nas colunas da excentricidade curta e a espessura medida nos perfís.

\begin{tabular}{|c|c|c|c|c|c|c|c|c|c|c|c|}
\hline \multirow[t]{2}{*}{$\begin{array}{l}\text { SEQÜÊNCIA } \\
\text { MILANKOVITCH }\end{array}$} & \multicolumn{2}{|c|}{$\begin{array}{c}\text { EXCENTRICIDADE } \\
\text { LONGA (400 ka) }\end{array}$} & \multirow{2}{*}{$\begin{array}{c}\text { EXCENTRICIDADE } \\
\text { CURTA (100ka) } \\
\text { Referência } \\
\end{array}$} & \multicolumn{2}{|c|}{$\begin{array}{c}\text { OBLLQÜIDADE } \\
(41 \mathrm{ka})\end{array}$} & \multicolumn{2}{|c|}{$\begin{array}{l}\text { PRECESSÃO } \\
\text { LONGA (23 ka) }\end{array}$} & \multicolumn{2}{|c|}{$\begin{array}{l}\text { PRECESSÄO } \\
\text { CURTA (19 ka) }\end{array}$} & \multirow{2}{*}{$\begin{array}{c}\text { ESPESSURA } \\
\text { Observada } \\
\end{array}$} & \multirow{2}{*}{\begin{tabular}{|c|} 
TAXA DE \\
ACUMULAÇÃOO \\
(cm/ka)
\end{tabular}} \\
\hline & Estimada & Observada & & Estimada & Observada & Estimada & Observada & Estimada & Observada & & \\
\hline SCGE-A & $68,0-38,8$ & 34,0 & $17,0-9,7$ & $7,0-3,8$ & $6,8-4,3$ & $3,9-2,2$ & $4,4-3,6$ & $3,2-1,8$ & $3,0-2,4$ & $17,0-11,0$ & $17,0-9,7$ \\
\hline SCGE-B & $218,2-130,8$ & 245,6 & $54,6-32,7$ & $22,4-13,4$ & $18,2-14$ & $12,6-7,5$ & $12,8-8,5$ & $10,4-6,2$ & $6,8-5,2$ & $52,0-22,0$ & $54,6-32,7$ \\
\hline SCGE-C & $89,6-53,6$ & 100,6 & $22,4-13,4$ & $9,2-5,4$ & $8,4-5,8$ & $5,2-3,1$ & $4,9-4,3$ & $4,3-2,5$ & $3,6-2,8$ & $25,2-5,0$ & $25,2-5,0$ \\
\hline SCGE-D/SCGE-E & $96,0-48,0$ & 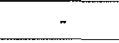 & $27,3-12,3$ & $11,2-5,5$ & $8,8-7,3$ & $6,3-2,8$ & $5,7-5,2$ & $5,2-2,3$ & 4,0 & $24,0-12,0$ & $27,3-12,0$ \\
\hline SCGE-FISCGE-G & 24,4 & 24,4 & 8,1 & 2,5 & 2,4 & 1,4 & 1,5 & 1,2 & $1,3-1,2$ & $8,0-5,0$ & $8,0-5,0$ \\
\hline SCGE-H/SCGE-I & $17,6-9,2$ & 15,5 & $4,4-2,3$ & $1,8-0,9$ & $1,7-1,2$ & $1,0-0,5$ & $1,0-0,8$ & $0,8-0,4$ & $1,0-0,8$ & $6,0-2,0$ & $6,0-2,0$ \\
\hline SCPE-CC/SCPE-Cf & 84 & - & 21 & 8,6 & $10,5-8,4$ & 4,8 & 4,4 & 4 & 3,4 & $25,0-18,0$ & $25,0-18,0$ \\
\hline SCPE-BfISCPE-Bh & 172 & - & 43,0 & 17,6 & 17,3 & 9,9 & $9,27,3$ & 8,2 & $9,2-7,3$ & $52,0-36,0$ & $52,0-36,0$ \\
\hline
\end{tabular}




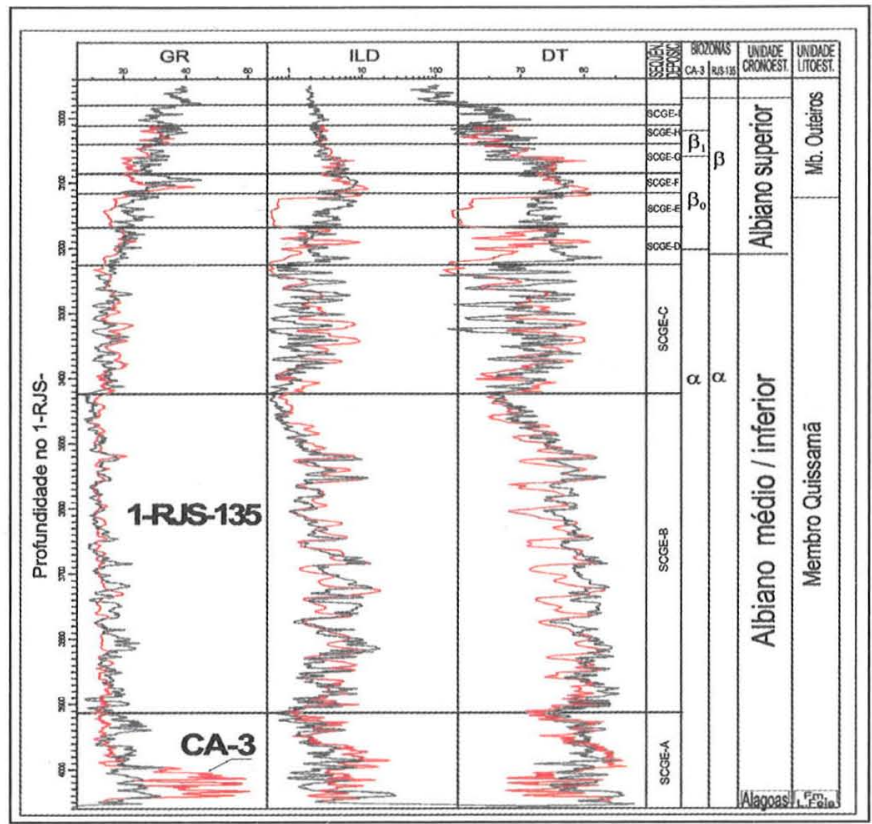

Figura.10: Justaposição entre dados geofísicos e geoquímicos do poço CA-3 contra a seção de referência (1-RJS-135). Os dados de RG, ILD e DT, são frutos de suavização pelo método Hamming, para 15 casos. A maior parte das unidades indicadas as colunas da direita é referente ao 1-RJS-135.

adoção dos valores entre 22,3 e 13,4 como espessuras máximas e mínimas para os ciclos sedimentares induzidos pela excentricidade curta na SCGE-C conduz a uma identificação satisfatória dos demais períodos orbitais, manifesto em agrupamentos de picos no periodograma. A comparação entre os valores estimados adotando estes limites e os picos destacados no periodograma pode ser acompanhada na Tabela 1.

É importante lembrar que, embora a combinação de resultados reduza a probabilidade de uma origem aleatória, ou autocíclica, para os ciclotemas, as espessuras indicadas nos periodogramas devem ser vistos como artefatos da solução matemática. No caso da SCGE-C, nenhum dos picos destacados coincide, ou se aproxima, dos valores medidos quando da caracterização das SCPE's. No entanto, a hipótese da influência orbital na sedimentação pode ser comprovada por meio de processamento de segmentos da SCGE-C, que registram taxas de acumulação mais homogêneas. Num exercício envolvendo seqüências compostas de pequena-escala SCPE-Cc a SCPE-Cf, a espessura indicada no periodograma para o ciclotema associado ao fenômeno de excentricidade curta coincide com valor médio calculado para o intervalo. As relações entre os diferentes períodos de Milankovitch acham-se razoavelmente ajustadas às espessuras de ciclotemas destacados no periodograma.

Não obstante outras SCGE's do Membro Quissamã registrarem variações na taxa de acumulação sedimentar, os "ruídos" observados nos periodogramas se mostraram de menor magnitude comparativamente àqueles da SCGE-C. É digno de destaque, o gráfico obtido para a série de pontos de RG da SCGE-B, que, em 491 m, congrega quatorze SCPE's, com espessuras entre 54 a $12 \mathrm{~m}$. Os eventos de excentricidade curta e obliqüidade estão marcados, de forma distinta e coerente, por ciclos sedimentares com valores médios de 40,9 e 16,4 m, respectivamente. Os picos relacionados aos dois fenômenos precessionais também são reconhecidos, embora sem a magnitude dos anteriormente citados. Já o pico de 245,6 m, destacado na solução matemática, pode ser considerado como relacionado à excentricidade longa, embora $o$ valor esteja um pouco acima da estimativa estabelecida a partir do ciclo sedimentar associado ao período de $100 \mathrm{ka}$.

Quanto aos gráficos referentes ao Membro Outeiro, os resultados são bem mais precisos, com destaque para a solução obtida nos dados de DT pertencentes as seqüências SCGE-F e SCGE-G. Incluído na figura 9, o periodograma pode ser considerado exemplar, com a presença picos marcando de forma inequívoca os ciclotemas associados aos principais períodos orbitais. Contribui para o resultado favorável relativa estabilidade da taxa de acomodação, expressa em doze ciclos sedimentares com espessuras que variam de 8 a $5 \mathrm{~m}$. Dentre as SCGE's, as seqüências SCGE-F e SCGE-G são as que registram o menor dispersão relativamente a espessura média.

CONSISTÊNCIA ESTRATIGRÁFICA Para avaliar a consistência lateral da solução estratigráfica obtida no 1-RJS135, examinou-se a seção albiana do poço CA-3, posicionado $4 \mathrm{~km}$ ao norte (Fig. 4). Apesar das peculiaridades estruturais e sedimentares, e da falta de uma linha sísmica passando pelos poços trabalhados, é possível obter uma excelente correlação estratigráfica entre as seções albianas. Esta conclusão baseia-se na justaposição das séries de medidas geofísicas do CA-3 às suas profundidades equivalentes no 1-RJS-135, processo este realizado por meio de transformação numérica linear simples, tendo como base de correlação data bio-e paraestratigráficos coevos em ambos os poços (Fig. 10).

A sedimentação carbonática Quissamã preservada no poço CA-3 se organiza em ciclos de shallowing-upward, com ordens de grandeza variando de centenas a poucos metros, num empilhamento sedimentar que permite a identificação todas as SCGE's presentes na seção de referência da Formação Macaé. A diferença mais marcante está na base da seção, onde há uma SCGE mais antiga do que a primeira do 1-RJS-135.

Esses primeiros depósitos carbonáticos albianos acumulados na região do CA-3, distribuída entre as profundidades de 3901 e 3872 m, definem a SCGE-X,que se subdivide em duas SCPE. O intervalo é constituído por dolomitos associados à ambiente de planície de maré (Spadini, comunicação pessoal). O comportamento nos perfis geofísicos indica uma maior argilosidade na base da seqüência, que se reduz drasticamente em direção ao topo, onde o incremento do processo de dolomitização torna o intervalo bem mais fechado. Esse aparente aumento no aporte continental é o aspecto mais sugestivo da presença de uma descontinuidade sedimentar separando as anidritas da Formação Lagoa Feia dos dolomitos da base do Macaé.

Quanto ao processo de dolomitização, observa-se que no poço CA-3 o fenômeno se estendeu por um período maior, com dolomitos sendo constatados desde a SCGE-X até a SCPE-Ad. Entre as hipóteses lembradas para justificar tal fato estão a maior argilosidade do intervalo, que poderia representar uma fonte importante de magnésio liberada durante a compactação, ou então a influência de recarga de água doce por aqüíferos ligados ao continente próximo. Há também de se considerar o modelo tectono-hidrológico proposto por Azevedo (2001), embora os dolomitos da SCGE-A não repousem sobre o pacote evaporítico. Uma interpretação mais consistente do problema recomenda estudos petrográficos e geoquímicos de detalhe, que não foram realizados nessa investigação.

No topo da seção albiana a diferença do CA-3 em relação ao 1-RJS-135 é marcada pela ausência da SCGE-I, indicando que o hiato no limite com o Cenomaniano teve maior expressão na primeira dessas seções.

Os resultados obtidos nos periodogramas das seções dos membros Quissamã e Outeiro são auspiciosos, porquanto confirmam a adequação da interpretação proposta à escala de tempo adotada. O empilhamento 41 ciclos de excentricidade curta, que 
compõem a primeira dessas unidades litoestratigráficas no 1RJS-135, indica um hiato da ordem de 2 Ma no pacote do Albiano inferior/médio. Seguindo o mesmo raciocínio, estima-se a existência de uma lacuna de rocha-tempo de $3 \mathrm{Ma}$ no Albiano superior no CA-3.

CONCLUSÕES Consolidou-se um modelo de identificação de seqüências e tratos de sistemas para sucessões carbonáticas, tendo como exemplo a seção de referência da Formação Macaé e estabelecendo correlação estratigráfica com seção coeva, a partir de padrões de perfis geofísicos e geoquímicos.

A plataforma carbonática albiana estudada registra dez SCGE's e 74 dezenas SCPE's, que se subdividem em numerosas seqüências elementares (SE). A indicação do controle halocinético na criação de espaço para a sedimentação dos ciclotemas de terceira ordem (as SCGE's) sustenta-se nos períodos irregulares destas seqüências, que variam de 0,3 a 1,4Ma. Os ciclos sedimentares organizados pelo fenômeno de excentricidade curta, com 100ka de duração, construíram as SCPE's, as unidades mais marcantes no registro sedimentar. Estes pacotes de rochas são constituídos por seqüências elementares (SE), num arranjo fractal onde são percebidos, respectivamente, os controles da precessão e da obliqüidade na formação destas unidades básicas e no conjunto de algumas delas.

O padrão de empilhamento estratal de shallowing-upward, dominante no Membro Quissamã, tem o trato transgressivo representado por calcilutitos da base do ciclo. As fácies que se sucedem, com granulometria crescente e associadas a níveis ener- géticos mais elevados, representam o trato de nível de mar alto. Como em outras seções carbonáticas examinadas, o trato de nível de mar baixo teve pouca expressão no período devido à fisiografia, desfavorável à sua acumulação e preservação.

Quando submetida a condições marinhas mais profundas, as respostas do sistema carbonático às variações relativas do nível do mar se fizeram com a acumulação rítmica de calciclutitos e margas, compondo as seqüências deposicionais elementares. Os calcilutitos desenvolveram-se no trato transgressivo e as margas, nos tratos de nível de mar alto e mar baixo subseqüente, em relação de concordância.

A análise de ciclos mostrou-se extremamente útil à compartimentação estratigráfica e à indicação de amplitudes temporais dos ciclotemas de várias ordens presentes nas seções, permitindo detalhamentos geocronológicos da ordem de 104 anos, em intervalos específicos. Os três fenômenos orbitais reconhecidos nas sucessões de rocha estudadas. $\mathrm{Na}$ área estudada, o número de SCPE's empilhadas e contadas indica a preservação de somente 7,4 do total de 13,3Ma estimados para o Albiano.

Agradecimentos À PETROBRÁS, patrimônio do nosso Povo, que espero e luto para vê-la sempre auxiliando o desenvolvimento do Brasil, e que autorizou a publicação desse artigo. Aos geólogos Spadini e Dimas, pelo apoio no estudo dos carbonatos. Ao Geólogo Azambuja, introdutor das discussões sobre ciclos sedimentares e pela coordenação desse número da RBG. Ao Geólogo Mitsuro Arai, revisor desse trabalho.

\section{Referências}

Azambuja Filho, N.C. 1990. The Oligo-Miocene turbidites and associated facies of the Campos basin, offshore Brazil. Tese de doutorado, Imperial College of London, Londres. $456 \mathrm{p}$.

Azevedo, R.L.M. 2001 O Albiano no Atlântico Sul: estratigrafia, paleoceanografia e relações globais. Tese de Doutorado, Universidade Federal do Rio Grande do Sul, Porto Alegre.. 401 p. 2 v.: il.

Azevedo, R.L.M.; Gomide, J.; Viviers, M.C. 1987. Geo-história da bacia de Campos, Brasil: do Albiano ao Mastrichtiano. Rev. Bras. Geoc., 17: 139-146.

Azevedo, R.L.M.; Gomide, J.; Viviers, M.C; Hashimoto, A.T.1987. Bioestratigrafia do Cretáceo marinho da Bacia de Campos. Rev. Bras. Geoc., 17: 147-153.

Bralower, T.J.; Fullagar, P.D.; Paull, C.K.; Dwyer, G.S.; Leckie, R.M. 1997. Mid-Cretaceous strontium-isotope stratigraphy of deep-sea sections. GSA Bulletin, 109 (10):. 1421-1442.

Berger, A. 1988. Milankovitch theory and climate. Reviews of Geophysis, 26 (4): 624-657.

Chang, H. K.; Kowsmann, R.O.; Figueiredo, A.M.F.; Bender, A.A. 1991 Novos conceitos sobre o desenvolvimento das bacias marginais do leste brasileiro. In: Raja Gabaglia, G.P.e Milani, E.J. (eds.) Origem e Evolução de Bacias Sedimentares. PETROBRAS, Rio de Janeiro. pp 269-289

Esteves, F.R.; Spadini, A.R.; Makoto, S. 1987. A sedimentação alboturoniana (Formação Macaé) da Bacia de Campos. In: SBG, Simp. Geol. Regional RJ-ES, 1. Anais .... p. 27-42.

Falkenhein, F.U.H. 1981. Carbonate microfacies and depositionalevolution of the Macaé Formation (Albian-Cenonanian) Campos Basin, Brazil. Tese de doutorado, University of Illinois, Urbana. p. 259.

Fischer, A.G. 1986. Climatic rhythms recorded in strata. Annual Review Earth Planetary Science, 14: 351-376.

Frakes, L. A.; Francis, J. E.; Syktus, J. I.. 1992. Climate modes of the Phanerozoic: The history of the Earth's climate over past 600 millions years. Cambridge University Press. $274 \mathrm{p}$.

Kendall, C.G.St.C. e Schlager, W. 1981. Carbonates and relative changes of sea level. Marine Geology, 44: 181-212.

Pasquier, J-B. e Strasser. A. 1997. Platform-to-basin correlation by highresolution sequence stratigraphy and cyclostratigraphy (Berriasian, Switzerland and France). Sedimentology, 44: 1071-1092.

Rangel, H.D.; Martins, F.A.L.; Esteves, F.R.; Feijo, F.J. 1994. Bacia de Campos. B. Geoci. Petrobras, 8: 203-217.

Sadler, P. M. 1994. The expected duration of upward-shallowing peritidal carbonate cycles and their terminal hiatuses. Geological Society of America Bulletin, 106: 791-802.

Seilacher, A. (eds.). Cycles and events in stratigraphy. Berlin: SringerVerlag. p. 617-657

Soreghan, G.S. e Dickison, W.R. 1994. Generic types of stratigraphic cycles controlled by eustasy. Geology, 22: 759-761.

Spadini, A. R. 1992. Processos deposicionais e ciclicidade em carbonatos albianos de plataforma rasa da Bacia de Campos. Dissertação de mestrado, Universidade Federal do Rio de Janeiro, Rio de Janeiro. P. 139 
Spadini, A.R. 1982. Calcários de granulação fina da Formação Macaé, Bacia de Campos. In: IBP, Cong. Bras. Geol. 2. Anais ... p. 1-18.

Vail, P.R.; Audemard, F.; Bowman, S.A.; Eisner, P.N.; Peres-Crus, C. 1991. The stratigraphic signatures of tectonics, eustasy and sedimentology- an overview. In: Einsele, G.; Ricken, W.;
Wright, V.P. e Burchette, T.P. 1996. Shallow-water carbonate environments. In: Reading, H.G (Edt.). Sedimentary Environments: Processes, Facies and Stratigraphy, Blakwell Science. p. 325-394. 